\title{
BENTUK SENI PERTUNJUKAN RONGGENG PASAMAN DI KABUPATEN PASAMAN SUMATERA BARAT
}

\author{
Kurniawan Fernando $^{1^{*}}$, Martarosa $^{2 *}$, Awerman $^{3^{*}}$ \\ Minat Pengkajian Musik Barat Program Pascasarjana \\ Institut Seni Indonesia Padangpanjang \\ Jl. Bahder Johan, Guguak Malintang, Padangpanjang, Kota Padangpanjang, 27126. \\ Sumatera Barat. Indonesia. \\ Email: kurniawanfernando90@gmail.com
}

\begin{abstract}
Abstrak
Penelitian ini bertujuan untuk mengetahui bentuk seni pertunjukan Ronggeng Pasaman di Kabupaten Pasaman, Sumatera Barat. Ronggeng Pasaman merupakan seni pertunjukan terdiri dari pantun, joget, dan musik, khususnya terdapat di Kabupaten Pasaman, Sumatera Barat. Bentuk pertunjukan Ronggeng Pasaman adalah menggabungkan keahlian berpantun sambil menari dengan iringan musik biola dan gendang. Pertunjukan dimulai pada malam hari, dan berakhir hingga menjelang pagi. Beberapa grup Ronggeng Pasaman yang berada di Kabupaten Pasaman saat ini juga menampilkan pertunjukan Ronggeng Pasaman yang dikemas lebih kekinian dan menggunakan alat musik modern, sehingga Ronggeng Pasaman bisa dinikmati dengan dua versi, yaitu tradisi dan modern. Adapun dalam pertunjukan Ronggeng Pasaman modern yaitu menggunakan instrumen musik keyboard dan tidak menampilkan penyanyi atau Anak Ronggeng yang berpenampilan seperti perempuan dalam pertunjukannya. Tentunya kemajuan teknologi dimanfaatkan para seniman dalam pertunjukan Ronggeng Pasaman agar kesenian tersebut tetap hidup, berkembang dan terus diminati masyarakatnya. Penelitian ini menggunakan metode kualitatif, bersifat deskripsi analitik, partisipan observan. Hasil penelitian menunjukkan bahwa pertunjukan Ronggeng Pasaman dalam bentuk tradisi ataupun dalam bentuk modern oleh masyarakatya diterima dengan baik dan juga didukung penuh oleh pemerintah setempat.
\end{abstract}

Kata Kunci: bentuk pertunjukan, ronggeng Pasaman Sumatera Barat.

\begin{abstract}
This study aims to find out the art form of Pasaman Ronggeng performances in Pasaman Regency, West Sumatra. Ronggeng Pasaman is a performance art consisting of pantun, joget, and music, especially in Pasaman Regency, West Sumatra. The form of the Ronggeng Pasaman show is combining bouncing skills while dancing to the accompaniment of violin and drum music. The show starts at night, and ends until early morning. Some Ronggeng Pasaman groups in Pasaman Regency also present Ronggeng Pasaman performances which are packed more recently and use modern musical instruments, so Ronggeng Pasaman can be enjoyed in two versions, namely traditional and modern. As for the modern Rongaman Ronggeng show, it uses keyboard music instruments and does not display Ronggeng singers or children who look like women in their performances. Of course, technological advances are utilized by the artists in the Ronggeng Pasaman show so that the art will continue to live, develop and continue to be in demand by the community. This study uses qualitative methods, is analytic description, observant participants. The results showed that the performance of Pasaman Ronggeng in the form of tradition or in modern form by the community was well received and was also fully supported by the local government.
\end{abstract}

Keywords: form of performance, ronggeng Pasaman West Sumatra.

\section{PENDAHULUAN}

Kabupaten Pasaman merupakan wilayah yang terdapat di Provinsi Sumatera Barat. Penduduk Kabupaten Pasaman terdiri dari suku Minangkabau, suku Mandailing dari Sumatera Utara, dan suku Jawa. Kabupaten Pasaman terdapat sebuah kesenian, masyarakat Pasaman menyebutnya dengan Ronggeng
Pasaman. Ronggeng Pasaman merupakan seni pertunjukan yang terdiri dari pantun, tari atau joget, dan di iringi musik. Ronggeng Pasaman khususnya terdapat di daerah Simpang Empat dan Simpang Tonang, Pasaman, Sumatera Barat (Takari, 2014: 61). Bentuk pertunjukan Ronggeng Pasaman yaitu menggabungkan keahlian berpantun sambil menari 


\section{Gorga Jurnal Seni Rupa \\ Volume 07 Nomor 02 \\ p-ISSN: 2301-5942 | e-ISSN: 2580-2380}

dan diiringan musik. Ronggeng Pasaman biasanya dipertunjukkan pada malam hari, dimulai pada pukul sepuluh malam hingga menjelang subuh sekitar pukul lima pagi. Tempat pertunjukan biasanya di tampilkan pada lapangan terbuka atau di pentas yang dibuat khusus. Ronggeng Pasaman ini biasanya dipertunjukkan dalam perhelatan perkawinan, perayaan hari kemerdekaan Indonesia, dan peringatan keagamaan Islam, seperti hari Raya Idul Fitri dan Idul Adha.

Pantun dalam pertunjukan Ronggeng Pasaman didendangkan atau dinyanyikan oleh seorang penampil wanita , penampil tersebut disebut dengan anak Ronggeng. Anak Ronggeng adalah laki-laki yang didandani seperti perempuan (Transvesti) dan memakai baju kurung. Jenis pantun yang dibawakan adalah pantun muda-mudi dinyanyikan mengikuti irama lagu, seperti lagu Cerai kasih, Kaparinyo, Buah Sempaya, Tari Payung, Mainang, Alah Sayang, Sinambang dan Si Kambang Baruih. Pantun-pantun yang didendangkan itu bersifat bebas dan lepas, tidak membentuk suatu kesatuan cerita. Pemain musik dalam pertunjukan Ronggeng Pasaman terdiri dari lima orang yaitu, satu orang menggesek biola, dua orang memukul gendang, satu orang memukul tamborin, dan satu orang memukul botol untuk menjaga tempo.

Beberapa grup Ronggeng Pasaman yang berada di Kabupaten Pasaman saat ini juga menampilkan pertunjukan Ronggeng Pasaman yang dikemas lebih kekinian dan menggunakan alat musik modern, tak kalah seperti pada pertunjukan musik orgen tunggal misalnya, yang mana menampilkan penyanyipenyanyi yang menarik dan pilihan lagu atau genre musik yang beragam, sehingga Ronggeng Pasaman bisa dinikmati dengan dua veri, yaitu tradisi dan modern. Dalam pertunjukan Ronggeng Pasaman yang dikemas dalam bentuk modern tersebut yaitu penyanyi tidak menggunakan anak Ronggeng, yaitu penyanyi laki-laki yang didandani seperti perempuan (Transvesti), namun penyanyi tersebut digantikan menjadi penyanyi perempuan atau laki-laki sebenarnya. Selain itu juga menambahkan instrument musik keyboard dan mengkolaborasikannya dengan instrument musik tradisi seperti biola dan gendang kedalam pertunjukan musik Ronggeng Pasaman, tentunya nuansa musik Ronggeng Pasaman yang ditampilkan menjadi sangat berbeda dibandingkan pertunjukan Ronggeng Pasaman tradisi lainnya.

Penelitian bentuk seni pertunjukan Ronggeng Pasaman di Kabupaten Pasaman Sumatera Barat ini menggunakan metode kualitatif dan deskriptif analisis dengan pendekatan multi-disiplin di bawah payung disiplin Musikologi. Metode penelitian kualitatif digunakan dalam penelitian ini karena data yang didapatkan tidak melalui prosedur statistik, melainkan didapatkan dari pengamatan pada manusia dalam kawasannya sendiri dan berhubungan dengan orangorang tersebut dalam bahasanya dan dalam peristilahannya.

Penelitian ini menerapkan metode Alan P. Merriam mengenai tiga tahapan, yaitu: (1) mengumpulkan data; (2) memilahnya kepada dua jenis analisis yakni (a) menelaah bahan-bahan Etnografi dan Etnologi yang dikumpulkan dengan cara mengkaji secara ilmiah dan rasional mengenai praktik musik, perilaku, dan konsep-konsep dalam masyarakat untuk melihat apakah sesuai dengan hipotesis dan rancangan awal, (b) analisis laboratorium terhadap bahan-bahan musik yang telah dikumpulkan, hal ini menuntut teknik dan terkadang alat bantu khusus dalam membuat transkrip dan analisis struktur musiknya; dan (3) data yang sudah dianalisis dan hasil yang sudah didapat diterapkan kembali pada masalah terkait, khususnya dalam musikologi dan lebih luas lagi dalam ilmu pengetahuan sosial dan humaniora (Merriam, 1964 :7). Selain itu, penelitian ini juga dilakukan dengan kerterlibatan langsung penulis pada proses pertunjukan musik, serta proses kehidupan sehari-hari masyarakat Andilan Duo Koto Pasaman.

\section{KAJIAN TEORI}

Pertunjukan menurut Schechner merupakan tindakan yang dikerangkakan, disajikan atau dipertontonkan untuk orang lain, dan tindakan-tindakan itu merupakan gagasan yang mendasari dari pertunjukan. Tindakan atau wujud perilaku yang disajikan dalam pertunjukan merupakan kualitas perilaku yang diperbaiki atau direstorasi. Artinya, yang ditampilkan bukanlah suatu yang biasa dan bersifat keseharian, tetapi bersifat luar biasa atau telah mengalami perestorasian atau perbaikan perilaku keseharian. Struktur pertunjukan Ronggeng Pasaman dibagi menjadi tiga tahap. Pertama persiapan, kedua pertunjukan, dan ketiga aftermath (Schechner dalam Asril 2016: 155).

Persiapan meliputi pemusik mempersiapkan diri untuk latihan, sedangkan penonton mempersiapkan diri untuk menonton pertunjukan Ronggeng Pasaman. Pertunjukan merupakan peristiwa pemusik dari grup Ronggeng Pasaman melakukan pementasan dan penonton menyaksikan pertunjukan Ronggeng Pasaman. Aftermath meliputi istirahat pemusik dari 


\author{
Gorga Jurnal Seni Rupa \\ Volume 07 Nomor 02 \\ p-ISSN: 2301-5942 | e-ISSN: 2580-2380
}

grup setelah usai bermain musik, serta membereskan peralatan dan instrument musik grup tersebut.

\section{Persiapan}

Persiapan pertunjukan dari grup Ronggeng Pasaman meliputi latihan rutin yaitu pada malam hari senin, selasa dan rabu malam. Latihan bertempat di rumah salah satu pemusik, tempat yang sudah dibuat khusus untuk latihan musik bersama. Sebelum latihan bersama, biasanya pemusik berkumbul berdiskusi bersama menceritakan kehidupan sosial keluarga, dan pekerjaan masing-masing. Diskusi bersifat santai, saling bertanya dan menjawab sesama pemusik. Diskusi tersebut membuat hubungan emosional semakin dekat, terbuka, saling pengertian yang menciptakan suasana kekeluargaan sesama pemusik.

Latihan musik disesuaikan dengan posisi keahlian masing-masing pemusik terhadap instrumennya. Pemusik terdiri dari beberapa orang pemain, yaitu satu orang pemain keyboard untuk pertunjukan Ronggeng Pasaman yang modern, satu orang pemain biola, satu orang pemain gendang, dan beberapa penyanyi. Ketika pemain musik sudah lengkap, maka pemain musik memiliki kesadaran masing-masing untuk mempersiapkan instrumen musik beserta pengeras suara yang telah disediakan. Setelah semua instrumen musik ditata sesuai kebutuhan pemusik. Pada awal pertunjukan Ronggeng Pasaman, ada bagian musik solo yaitu suling dan bagian dendang yang dinyanyikan penyanyi laki-laki. pemain musik suling yang akan menjadi pembuka atau mengawali pertunjukan musik dengan mengiringi alunan vokal tradisi yang didendangkan oleh penyanyi.

Setelah selesai memainkan musik untuk pembukaan, maka pemusik mulai memainkan lagu-lagu tradisi Ronggeng Pasaman. Lagu-lagu tradisi Ronggeng Pasaman yang dilatih untuk dibawakan saat pertunjukan atau pementasan nantinya, diantaranya yaitu lagu; Ka Guo, Bio-bio, Rosmali, Sikambang Rang Jauah, Aliatun, Sikambang Simpang Tonang, Bateh Tontong, Kaparinyo Padang, Ta Ijo Ijo, Anak Dagang, Filosofi Incir Aek, Mainang Sibolga dan Talak Tigo. Susunan latihan yaitu dengan menyelasaikan satu lagu, kemudian dilanjutkan dengan melatih lagu lainnya, tentunya lagu yang dilatih lainnya melalui kesepakatan antara pemain musik dengan penyanyi. Fungsi dari latihan yaitu untuk meyamakan rasa musikal sesama pemusik, dan persiapan untuk pementasan-pementasan berikutnya. Dengan seringnya berlatih bersama, pemusik meyakini bahwa permainan musik yang akan ditampilkan akan semakin kompak, rapi dan enak didengar.

\section{Pertunjukan}

Untuk mendapatkan permainan yang pas, sesama anggota grup mencari pemain musik yang peka terhadap bunyi nada ataupun melodi dalam bermain musik bersama. Dalam pertunjukan Ronggeng Pasaman yang sudah modern misalnya, ada sedikitnya dari tiga pemain biola bisa bermain bersama dan bisa memainkan atau menebak melodi untuk biola yang dimainkan dengan akord pada instrumen keyboard. Setelah menetapkan pemain musik biola yang pas untuk berkolaborasi dengan keyboard, maka dilakukan proses latihan bersama. Seiring berjalannya waktu dan seringnya melakukan pertunjukan, masing-masing individu sudah memahami karakter dari cara bermain musik sesama pemusik. Sehingga pemusik tidak mengalami permasalahan dalam permainan musik bersama.

Pertunjukan Ronggeng Pasaman biasanya bertepatan di saat hari libur atau di saat acara-acara tertentu. Pertunjukan Ronggeng Pasaman dipertunjukkan dalam peringatan keagamaan Islam, seperti hari Raya Idul Fitri dan Idul Adha, perhelatan perkawinan, perayaan hari kemerdekaan Indonesia, dan acara dalam undangan pemerintahan. Pertunjukan Ronggeng Pasaman dipertunjukkan pada malam hari, dimulai pukul delapan malam hingga menjelang subuh sekitar pukul lima pagi. Persiapan yang dilakukan sebelum pertunjukan yaitu, gotong royong sesama pemusik mengangkat sound system dan perlengkapan alat musik naik ke atas mobil yang sudah disiapkan dan dibawa kelokasi atau tempat pertunjukan yang telah disediakan warga masyarakat yang mengundang. Setibanya dilokasi atau tempat pertunjukan, dilakukan pemasangan alat baik itu alat musik maupun sound system, dengan menyesuaikan besar atau kecilnya pentas pertunjukan yang sudah disediakan warga masyarakat. Setelah melakukan pemasangan alat, maka dilakukan pengecekan bunyi sound system, kemudian pengesetan instrumen musik sesuai dengan formasi masing-masing pemusik. Setelah memastikan bunyi sound system dan instrument musik enak didengar, maka pertunjukan Ronggeng Pasaman akan dimulai.

Pada awal pertunjukan Ronggeng Pasaman, ada bagian musik solo yaitu suling dan bagian dendang yang dinyanyikan penyanyi laki-laki. Pemain musik suling menjadi pembukak atau mengawali pertunjukan musik dengan mengiringi alunan vocal tradisi yang didendangkan oleh sipenyanyi. Setelah selesai memainkan musik untuk pembukaan, pembawa acara memberi kata pembukaan dengan memberi sambutan 


\section{Gorga Jurnal Seni Rupa \\ Volume 07 Nomor 02 \\ p-ISSN: 2301-5942 | e-ISSN: 2580-2380}

selamat datang kepada penonton pertunjukan yang datang. Ketika sambutan untuk pembukaan telah dilakukan, maka instrumen musik dimainkan, musik yang dimainkan merupakan bagian intro musik dari salah satu lagu tradisi Ronggeng Pasaman yang akan dimainkan nantinya, bagian intro musik hanya dimainkan oleh pemain musik saja, tanpa ada suara vocal. Salah satu pemusik mengajak pemusik lainnya bermain musik menikmatinya dengan santai. Ketika situasi bermain musik dengan santai ini menciptakan suasana keakraban, kekeluargaan sesama pemain musik. Sesekali pujian sesama pemain musik terucap, karena merasakan kepuasan dengan intrumen musik yang memainkan musik-musik tradisi Ronggeng Pasaman. Pada bagian kedua, pemusik memainkan beberapa lagu tradisi Ronggeng Pasaman berduet antara penyanyi laki-laki dan penyanyi perempuan. Suasana pun semakin ramai, tempo permainan sudah mulai cepat. Terlihat dari ekspresi para penonton yang menyaksikan pertunjukan bersemangat, antusias, canda tawa, serta penonton pun ingin ikut berjoget naik ke atas pentas pertunjukan. Panitia acara menyediakan kursi untuk penonton dalam menikmati pertunjukan musik, namun banyak juga penonton yang tidak kedapatan kursi dan akhirnya memilih untuk berdiri.

Pertunjukan Ronggeng Pasaman memiliki aturan saat di atas pentas atau panggung pertunjukan, seperti membatasi penonton yang ingin bernyanyi sambil berbalas pantun, berjoget bersama penyanyi. Tentunya aturan tersebut dibuat demi kelancaran pertunjukan. Ketika pertunjukan musik sedang berlangsung, sebagian penonton ikut berjoget bersama penonton lainnya berjoget di depan panggung pertunjukan, sesekali ada penonton yang usil naik ke atas pentas pertunjukan, awalnya satu penonton saja yang naik untuk berjoget bersama penyanyi, lama kelamaan menyusul penonton lainnya naik keatas panggung pertunjukan. Pembawa acara sangat diperlukan dalam pertunjukan Ronggeng Pasaman, di sini pembawa acara harus cakap berinteraksi dengan penonton pertunjukan. Pembawa acara juga harus bisa mengendalikan penonton yang melanggar atau mengganggu kelancaran di saat pertunjukan musik sedang berlangsung. Naik turunnya kemeriahan dan kualitas acara ditentukan oleh interaksi pembawa acara baik dengan pemain musik, penyanyi, maupun masyarakat yang sedang menonton pertunjukan. Senada dengan itu Rosa menyatakan sebagai berikut.

"Pembawa acara dalam pertunjukan Ronggeng Pasaman sangat diperlukan sekali, karna sebagai pembawa acara saya bisa menjembatani interaksi sesama penonton maupun pemusik. Saya sebagai pembawa acara harus peka terhadap penonton, banyak tipe penonton dalam menikmati pertunjukan Ronggeng Pasaman, diantaranya penonton yang biasanya anak muda yang sedang mabuk selepas meneguk minuman keras atau alkohol dan membuat kerusuhan atau kegaduhan dengan penonton yang lainnya, disini peran saya sebagai pembawa acara yang akan menanganinya. Biasanya cara saya menangani penonton yang rusuh yaitu dengan cara menghampirinya dan mengajak mereka bernyanyi ataupun berjoget bersama, dan seketika penonton yang rusuh tadi pun menjadi tenang, disaat itu saya menasehati mereka dengan menggunakan bahasa yang tidak menyinggung. Terbukti selama pertunjukan Ronggeng Pasaman berlangsung, penonton menikmati pertunjukan dengan tertib hingga sampai akhir pertunjukan selesa". (Wawancara: Rosa, di Simpang Tonang, Kecamatan Duo Koto, Kabupaten Pasaman, 2018).

Pada pertunjukan Ronggeng Pasaman juga terjadi persaingan, persaingan yang dimaksud yaitu aksi berbalas pantun di atas pentas pertunjukan antara penyanyi dari grup dengan penyanyi yang berasal dari penonton. Penonton dalam hal ini dilibatkan dalam pertunjukan. Adapun aksi berbalas pantun tersebut, yaitu dimana penyanyi yang berasal dari penonton tersebut dengan lirik pantun yang dinyanyikan merayu penyanyi perempuan dari grup, dan rayuan tersebut juga dibalas dengan spontan oleh penyanyi perempuan dari grup tersebut. Ketika aksi berbalas pantun antara penyanyi dari grup dengan penyanyi dari penonton tersebut, membuat suasana pertunjukan menjadi meriah dan heboh dengan tepuk tangan dan teriakan dari pemusik maupun penonton pertunjukan, terkadang hal ini membuat penonton lainnya ikut serta dalam pertunjukan untuk berbalas pantun dengan penyanyi dari grup tersebut dan ada juga penonton yang ikut naik ke atas pentas pertunjukan hanya untuk ikut berjoged bersama.

Pedagang sangat banyak ditemukan di saat pertunjukan Ronggeng Pasaman berlangsung, pedagang memanfaatkan moment ini untuk meraih keuntungan dengan cara berjualan. Adapun pedagang terdiri dari penjual makanan, minuman, jajanan khas tradisional, mainan anak-anak, dan bahkan ada juga yang menjual pakaian.

\section{Aftermarth}

Aftermarth ialah kegiatan yang dilakukan setelah pertunjukan (Schechner dalam Asril, 2016: 218). Pada bagian ketiga ini yaitu kegiatan mengembalikan 


\section{Gorga Jurnal Seni Rupa \\ Volume 07 Nomor 02 \\ p-ISSN: 2301-5942 | e-ISSN: 2580-2380}

kembali instrumen musik dan sound system atau pengeras suara pada tempat penyimpanan di rumah Ijal. Aktivitas pengembalian instrumen musik dilakukan melalui kesadaran tiap pemusik. Rasa saling memiliki terhadap instrumen musik terlihat dari cara memainkan dan merawatnya dengan cara membersihkan debu atau kotoran yang menempel pada instrumen tersebut. Dengan adanya rasa saling memiliki diantara sesama pemusik, maka terwujudlah rasa kebersamaan, solidaritas, saling mengerti, dan rasa kekeluargaan.

Setelah selesai dari aktivitas pengembalian alat-alat dan instrumen yang digunakaan saat pertunjukan secara bergotong royong menyimpannya kerumah atau studio, biasanya para pemusik melakukan diskusi evaluasi diteras rumah dari ketua kelompok. Diskusi tersebut biasanya membahas apa saja kekurangan atau hal-hal yang dialami selama pertunjukan berlangsung, seperti pembahasan aransemen permaianan musik, kostum, skenario pantun yang akan dinyanyikan. Tentunya diskusi ini ialah untuk mengevaluasi apaapa saja kekurangan-kekurangan yang didapat saat pertunjukan dan mencari solusi bersama-sama guna untuk kemajuan grup. Biasanya diskusi berakhir dengan canda, tawa sesama pemusik selepas penat melakukan pertunjukan bersama. Kemudian dilakukan pembagian honor dan disesuaikan dengan bayaran dari yang mengundang.

\section{METODE PENELITIAN}

Untuk meningkatkan pemahaman pada objek penelitian bentuk seni pertunjukan Ronggeng Pasaman di Kabupaten Pasaman Sumatera Barat, salah satu langkah penting yang harus di persiapkan dalam proses kajian terhadap permasalahan yang di teliti adalah mencari metode yang tepat serta efisien dalam pengumpulan data di lapangan. Penulis dalam kajian ini menggunakan metode penelitian di antara, Seperti yang diungkapkan Ruth T. Watanabe dalam bukunya Introduction to Music Research, menjelaskan beberapa metode penelitian dasar dalam musik; (1) Perkembangannya, dimana proses evolusi subjek dipelajari; (2) Analisis, di mana subjek dipisahkan dan direkonstruksi untuk mempelajari mengapa dan bagaimana fungsinya; (3) Teoritis, dimana subjek terkait dengan konsep seperti bentuk, harmoni, tandingan, dan perangkat komposisi; (4) Komparatif, dimana beberapa elemen dapat diperiksa untuk titik kesamaan; dan sebaliknya, kontras, dimana titik perbedaan dicatat (Watanabe, 1967: 5).

Melalui empat metode penelitian musik Watanabe, maka pengetahuan dari seni pertunjukan Ronggeng
Pasaman akan membantu penulis dalam mengkaji permasalahan. Yaitu dengan kehadiran seni pertunjukan Ronggeng Pasaman di tengah-tengah masyarakat Pasaman, menikmati pertunjukan Ronggeng Pasaman dalam bentuk tradisi dan modern.

Penelitian bentuk seni pertunjukan Ronggeng Pasaman di Kabupaten Pasaman Sumatera Barat ini dilakukan dengan keterlibatan langsung penulis dalam proses pertunjukannya. Seperti mengamati aktivitasaktivitas perilaku masyarakat Pasaman dalam menonton pertunjukan musik. Maka dari itu, penelitian ini menggunakan data primer, dan data sekunder, dan data pendukung dari lapangan.

Sumber data primer adalah pemusik pelaku utama pemusik Ronggeng Pasaman dalam pertunjukan, sementara data sekunder adalah penonton pertunjukan Ronggeng Pasaman ketika pertunjukan sedang berlangsung, sementara data pendukung adalah tokoh masyarakat dan budayawan yang mengerti adat istiadat, untuk memberikan informasi mengenai masyarakat Kabupaten Pasaman Sumatera Barat. Metode penelitian kualitatif pengumpulan data dari lapangan dengan teknik pengamatan, keterlibatan, wawancara, perekaman audio visual, dan analisa data.

Lokasi penelitian Ronggeng Pasaman grup Ganto Saroha berada di Kecamatan Duo Koto Kabupaten Pasaman Sumatera Barat. Penelitan bentuk seni pertunjukan Ronggeng Pasaman di Kabupaten Pasaman Sumatera Barat ini dilakukan pada acara, seperti perhelatan perkawinan dan peringatan keagamaan Islam yaitu hari Raya Idul Fitri dan Idul Adha. Pertunjukan Ronggeng Pasaman dimulai pada malam hari sekitar pukul 19.00 WIB sampai menjelang pagi sekitar pukul 03.00 WIB.

\section{HASIL DAN PEMBAHASAN}

\section{Hasil Penelitian}

Pertunjukan Ronggeng Pasaman dalam bentuk tradisi ataupun dalam bentuk modern, masyarakatnya sangat menerima dengan baik, baik itu anak-anak, remaja, maupun orang tua. Adapun dalam pertunjukan Ronggeng Pasaman yang menggunakan instrumen musik keyboard dan tidak menampilkan penyanyi atau Anak Ronggeng yang berpenampilan seperti perempuan dalam pertunjukannya, menjadi tontonan atau hiburan berupa pertunjukan baru bagi masyarakat Pasaman. Tentunya kemajuan teknologi saat ini dimanfaatkan para seniman, agar kesenian Ronggeng di Pasaman tetap hidup, berkembang dan terus dinikmati masyarakat. 
2.Pembahasan Penelitian

Penelitian ini bertujuan untuk mengetahui bentuk seni pertunjukan Ronggeng Pasaman di Kabupaten Pasaman, Sumatera Barat. Beberapa grup Ronggeng Pasaman yang berada di Kabupaten Pasaman saat ini juga menampilkan pertunjukan Ronggeng Pasaman yang dikemas lebih kekinian dan menggunakan alat musik modern, sehingga Ronggeng Pasaman bisa dinikmati dengan dua versi, yaitu tradisi dan modern. Adapun dalam pertunjukan Ronggeng Pasaman modern yaitu menggunakan instrumen musik keyboard dan tidak menampilkan penyanyi atau Anak Ronggeng yang berpenampilan seperti perempuan dalam pertunjukannya (Transvesti).

\section{KESIMPULAN DAN SARAN}

\section{Kesimpulan}

Pertunjukan Ronggeng Pasaman bisa dinikmati dengan dua versi, yaitu tradisi dan modern. Tentunya kemajuan teknologi dimanfaatkan para seniman dalam pertunjukan Ronggeng Pasaman agar kesenian tersebut tetap hidup, berkembang dan terus diminati masyarakatnya. Tentunya kemajuan teknologi dimanfaatkan para seniman dalam pertunjukan Ronggeng Pasaman agar kesenian tersebut tetap hidup, berkembang dan terus diminati masyarakatnya.

\section{Saran}

Saran yang dapat diberikan kesimpulan terkait dengan penelitian ini adalah agar seluruh masyarakat Pasaman terkhusus generasi muda agar terus mengembangkan, melestarikan dan menjaga kesenian tradisi daerahnya, terkhusus kepada pemerintahan setempat agar memberi perhatian, mensupport dan memfasilitasi para seniman Ronggeng Pasaman agar seni pertunjukan Ronggeng Pasaman terus berkembang dan banyak diminati masyarakatnya.

\section{DAFTAR RUJUKAN}

Asril. 2016, Tabuik: Pertunjukan Budaya Hibrid

Masyarakat Kota Pariaman Sumatra

Barat. Disertasi. Yogyakarta: ISI.

Merriam, Alan P. 1999, Terjemahan: Triyono

Bramantyo. Antropologi Musik.

Yogyakarta: Institut Seni Indonesia

Yogyakarta.

Schecner, Richard. 2003. Performance Theory.

London dan New York:

Routledge.

Takari, Muhammad. 2014. Ronggeng dan Serampang

Dua Belas dalam Kajian Ilmu-ilmu

Seni. Medan : USU Press.

Watanabe, Ruth T. 1967. Introduction to Music

Research.New Jersey: Prentice Hall. 